\title{
The Biology of Flowering of Some Pamir-Alai Species of the Genus ferula $\mathrm{L}$.
}

\author{
Olimjon N. Avalbaev \\ Jizzakh State Pedagogical Institute, Jizzakh, Uzbekistan \\ Email: avalbayev7788@mail.ru
}

How to cite this paper: Avalbaev, O.N. (2018) The Biology of Flowering of Some Pamir-Alai Species of the Genus ferula L. American Journal of Plant Sciences, 9, 1740-1746.

https://doi.org/10.4236/ajps.2018.98126

Received: July 3, 2018

Accepted: July 28, 2018

Published: July 31, 2018

Copyright $\odot 2018$ by author and Scientific Research Publishing Inc. This work is licensed under the Creative Commons Attribution-NonCommercial International License (CC BY-NC 4.0). http://creativecommons.org/licenses/by-nc/4.0/ (c) (i) (8) Open Access

\begin{abstract}
The sources about the seasonal and blossoming biology of some Ferula L. ( $F$ angrenii, F. ovina, F. dshizakensis, $F$. helenae) types which can be found in Western Pamir-Alay have been given in the article.

\section{Keywords}

Proteandria, Ferula, Monocarp, Polycarp, Paracodia, Generative
\end{abstract}

\section{Introduction}

Species of the genus Ferula are the most common species of the family Apiaceae L. (180-200), in the Western Pamir-Alai there are 34 species. Species of this genus are essential oil, fodder, honey, medicinal, starchy, aromatic, food and technical plants [1] [2] [3].

Since the 80 years of the last century, chemists in Uzbekistan have determined the structure of more than 100 species of the genus Ferula, of which more than 150 chemical compounds-coumarins, esters, lactones have been isolated. Based on these compounds, pharmacologists have created several new drugs [1] [3].

We have found that in the Western Pamir-Alai there are 34 species of the genus Ferula and they occupy a special place in the vegetation. Among them there are endemic species that are found only in the Western Pamir-Alai. For example, $F$. nuratavica occurs only on the ridge of Nuratau and $F$. helenae on the remnant mountains of the ridge of Nuratau (relict mountain Pistalitau and Balykli) [4] [5].

U. Rakhmankulov [3] has been studied the biology and resources of species of the genus Ferula in the Western Tien Shan, but the biology and resources of the Pamir-Alai species have been poorly studied.

This article is devoted to studying the biology of flowering of some western 
Pamir-Alai species Ferula.

\section{Research Objects and Methods}

When studying the biology of flowering, we used the works of T. A. Rabotnova, V. F. Shamurina, E. V. Tyurina and others, I. F. Satsyperova and others, A. N. Ponomareva et al. [6] [7] [8] [9] [10].

Observations on the flowering and fruiting of $F$. helenae were carried out in 2010-2011. On remnant on the mountain ridge Nuratau (near the village of Balykli), and the species F. angreni, F. ovina, F. dshizakensis-near the gate of Amir Temur (north-eastern part of the Turkestan ridge).

\section{Results and Discussions}

Of the three species studied ( $F$. angrenii, F. ovina, $F$. dshizakensis) are polycarp, F. helenae monokarp. Polycarp species bloom for $4-5$ years of vegetation and fruiting for 10 - 15 years. They form 1 - 3 generative shoots. Monocarp species- $F$. helenae forms one generative shoot and blooms from 7 - 8 years of vegetation, then dies off. Inflorescence of species of the genus Ferula complex umbrella-consists of numerous lateral axes. According to the classification of Troll, the synflorescence of Ferula belongs to a polycyclic type, deprived of a terminal flower. A complex umbrella is considered as a derivative of a panicle with reduced interstices of the main axis, which demonstrates one of the stages of this reduction. In Ferula species, umbrellas are collected in typical complex umbrellas. An umbrella-type branching, that is, the arrangement of several axes in the axils of strongly converging leaves (often reduced, separated by shorter internodes) is characteristic of the representatives of this family Apiaceae. For members of the genus Ferula is characteristic, the grouping of the axes into the umbrella, and umbrellas themselves branch along the same principle several times until the axes of the next branching order end in flowers. Usually there are 3 orders of magnitude.

In all the species studied, the inflorescence is a triple complex umbrella consisting of a plurality of umbrellas. For example, $F$. angrenii from the main axis of the inflorescence leave the lateral axes (paracodia) I, II (sometimes III) of order, bearing at the ends of the umbrella, which are called umbrellas of a complex umbrella. The first lateral axis (paracodia) in all the studied Pamir-Alai species of the genus Ferula appears in the sinuses of $4-8$ stem leaves. Characteristics of generative shoots of species of the genus Ferula are presented in Table 1 .

The length of the paracodia is different, but there is a decrease in its upward stalk. Each axis ends with umbrella and flowers. The first-order axis (central umbrella) ends with umbrellas with bisexual flowers. On each axis there are from 2 to 5 lateral, male umbrellas. The number of umbrellas and flowers decreases from bottom to top. The length of the lateral axes ranges from $5-8 \mathrm{~cm}$ in F. ovina, F. angrenii, $F$. dshizakensis to $20-30 \mathrm{~cm}$. On each paralysis there are from 2 to 3 - 5 lateral (staminate) umbrellas from 6 to $18 \mathrm{~cm}$ long. The number 
Table 1. Characteristics of generative shoots of species of the genus Ferula.

\begin{tabular}{cccc}
\hline Species & Number of paracodia & Central umbrella flower & $\begin{array}{c}\text { Lateral umbrella } \\
\text { flower }\end{array}$ \\
\cline { 2 - 4 } & \multicolumn{3}{c}{ Average, a piece } \\
\hline F. helenae & $14-16$ & $12-13$ & 4 \\
F. ovina & $8-9$ & $8-9$ & 2 \\
F. angreni & $15-17$ & $12-13$ & $3-5$ \\
F. dshizakensis & $12-14$ & $9-10$ & 2 \\
\hline
\end{tabular}

of paracodia also varies from 8 - 9 (in F. ovina), to $12-16$ (F. angrenii, F. dshizakensis, F. helenae). In the species of the genus Ferula, we have observed the presence of bisexual, functionally male (potentially bisexual) and transitional flowers between them, which allows us to classify them, like many umbelliferous ones, into and romonoenic plants [5] [8] [10].

All the flowers consist of 5 yellow petals, 5 stamens and a pistil. Petals are oval, narrowed at the apex. Pestle 1 with 2 carpels (ovary semi-negative, syncarpous, two-three cavity). Bisexual flowers differ from males by having a pistil with a well developed column and an ovary; in male flowers, it is usually rudimentary, and instead of the ovary they have a disc on which nectar is released during flowering. Male flowers also have 5 petals, 5 stamens, nectare disc, but are devoid of pestle. Nectare disk of smaller sizes. After the formation of the inflorescence, the budding phase begins. Flowers blossom acropeately, from the base to the top, as a result of which the young are located closer to the top, and the old ones are toward the base. This pattern applies to both the umbrella as a whole and umbrellas. The beginning of the opening of the flower is characterized by the alternate bending of the petals to the laterals. The color of the petals gradually changes from greenish-yellow to light yellow. In the period of full bloom, the petals become whitish. Following the bending of 1 or 2 petals, the stamen filaments, which are in the bud in the bent state, are alternately straightened and occupy an upright position. The beginning of straightening of stamens coincides with the beginning of nectar and the active flight of insect pollinators [9] [10].

Bisexual flowers, located in the central umbrellas of the paracodia, open from 6 to 22 hours. In nature, the peak opening of flowers in F. ovina, F. angrenii, $F$. dshizakensis falls on 12 - 14 hours: in F. helenae-by 10 - 12. Dynamics of diurnal flowering of some species of the genus Ferula are presented in Table 2.

In the staminate flowers of monocarp species located on the lateral umbrellas, the flowering peak is $9-14$ hours, and in polycarp flowers-at $12-18$. Flowering of bisexual flowers in the monocarp $F$. helenae lasts $6-7$ days, and in polycarps-F. ovina, F. angrenii, F. dshizakensis 6 - 10 days. Staminate flowers are located in the lateral umbrellas, both in monocarp and in polycarp, bloom 3 - 4 days after the beginning of flowering of bisexual flowers. In the monocarp $F$. helenae, they bloom 7 - 9 days, in polycarp forms-F. ovina, F. angrenii, F. dshizakensis 6 - 10. The peak of flowering in monocarp $F$. helenae is observed at $10-13$ hours, in 
Table 2. The dynamics of daily flowering of some species of the genus Ferula.

\begin{tabular}{|c|c|c|c|c|c|c|c|c|c|c|}
\hline \multirow{2}{*}{ Date } & \multicolumn{9}{|c|}{ Time } & \multirow[b]{2}{*}{ Tota } \\
\hline & 6 & 8 & 10 & 12 & 14 & 16 & 18 & 20 & 22 & \\
\hline \multicolumn{11}{|c|}{ F. helenae } \\
\hline 16.05 .2010 & 2 & 14 & 22 & 29 & 21 & 14 & 9 & 5 & - & 116 \\
\hline \multicolumn{11}{|c|}{ F. dshizakensis } \\
\hline 17.05 .2011 & - & 9 & 14 & 20 & 27 & 17 & 8 & 7 & - & 102 \\
\hline \multicolumn{11}{|c|}{ F. angrenii } \\
\hline 20.05 .2010 & - & 11 & 19 & 26 & 31 & 22 & 11 & 9 & 2 & 131 \\
\hline \multicolumn{11}{|c|}{ F. ovina } \\
\hline 23.05 .2011 & 1 & 8 & 15 & 23 & 29 & 19 & 8 & 7 & - & 110 \\
\hline
\end{tabular}

polycarps-at $12-18$. The maximum opening of staminate flowers in a monocarp is noted on the $2-3^{\text {rd }}$ day of flowering, in polycarps-on the $3^{\text {rd }}-6^{\text {th }}$ day (Figure 1).

The blossoming of flowers within umbrellas and umbrellas as a whole occurs in a strict sequence, which is also found in other representatives of Apiaceae (Figure 1, Figure 2). Thus, the male phase of flowering on shoots of higher orders coincides with the period of a mature pestle on shoots of lower orders, where blooming staminate flowers at this time are few. This enables self-pollination within one individual. Uniformity of plant blooms ensures the presence of individuals in different phases of development of flowers, and hence cross-pollination. The highest percentage of seeded seeds, both in dry and rainy weather, occurs on the $6^{\text {th }}-7^{\text {th }}$ day of flowering, which coincides with the period of discrepancy in the column. Within the inflorescence, the duration of flowering of the flowers is different, but a general pattern is revealed: on the lower paracodia the flowering lasts longer than on the upper ones. Monocarp F. helenae on the paragliding located in the lower part of the inflorescence, more flowers are formed than on the upper ones. Thus, in $F$. helenae, the third paracodia is carried on 337 - 461 flowers in central umbrellas, and the upper ones are from 241 - 345 pcs. Polycarps - F. ovina, F. angrenii, F. dshizakensis on the lower paragliding are formed on 203 - 257 flowers, on the upper-only 143 - 174. The number of flowers located on the paragliding of the lateral umbrellas (staminate), in all studied species increases from the bottom up. The period of flowering of one plant (from the moment of the first flower's bloom to the withering of the latter) depends on the number of flower-shoots (inflorescences) and climatic factors. Monocarp F. helenae blooms 6 - 7 days, polycarps F. ovina, F. angrenii, F. dshizakensis-from 6 to 10. Within one generative escape in polycarp blossoms lasts an average of 4.2 days (from 3.5 to 6.5). Blooming of bisexual flowers in polycarps continues on average 28 hours. In bisexual flowers, the anthers fall off, and then the stamen filaments occur at the end of the $1^{\text {st }}$ and $2^{\text {nd }}$ day of flowering, in functionally male flowers-on the $2^{\text {nd }}-3^{\text {rd }}$ day. The staminate phase lasts 


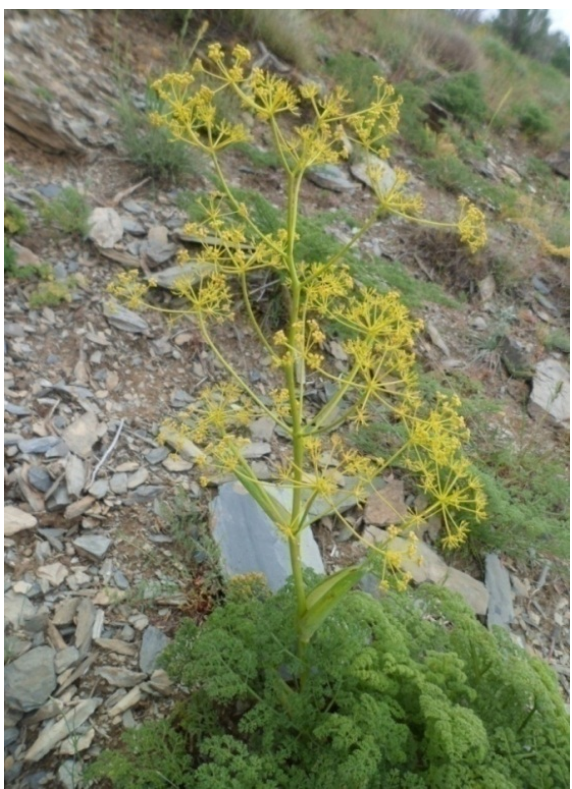

(a)

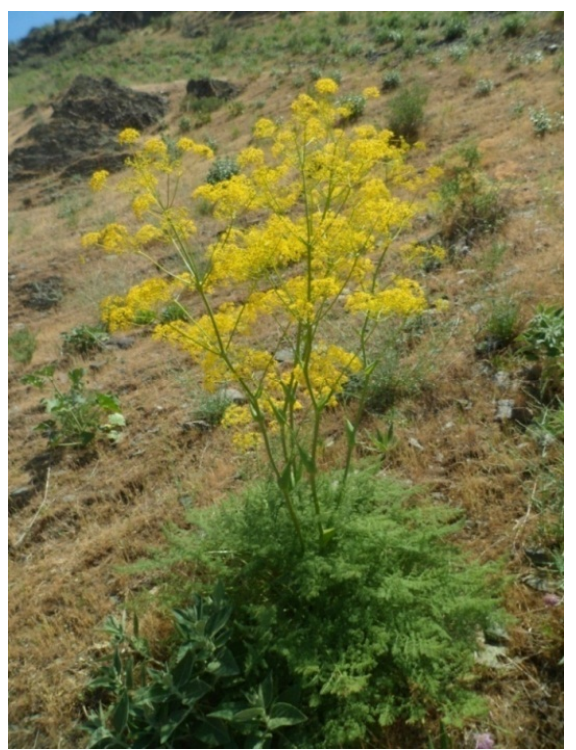

(c)

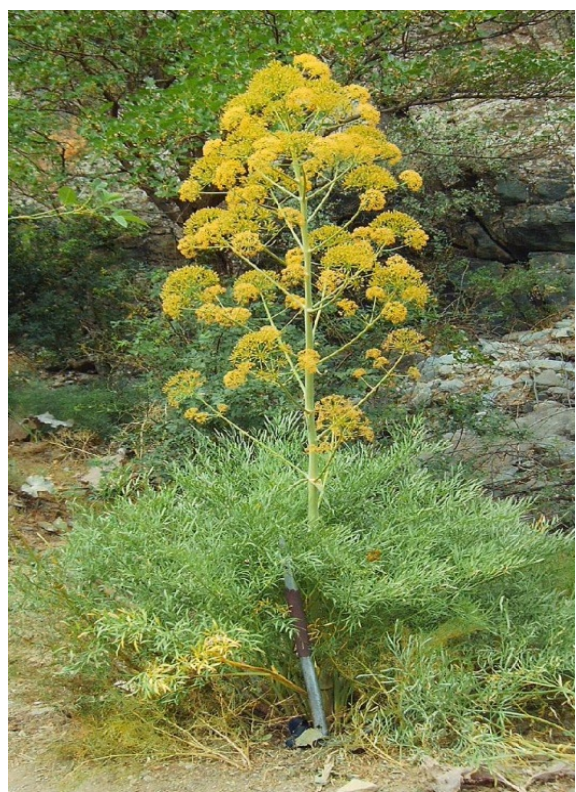

(b)

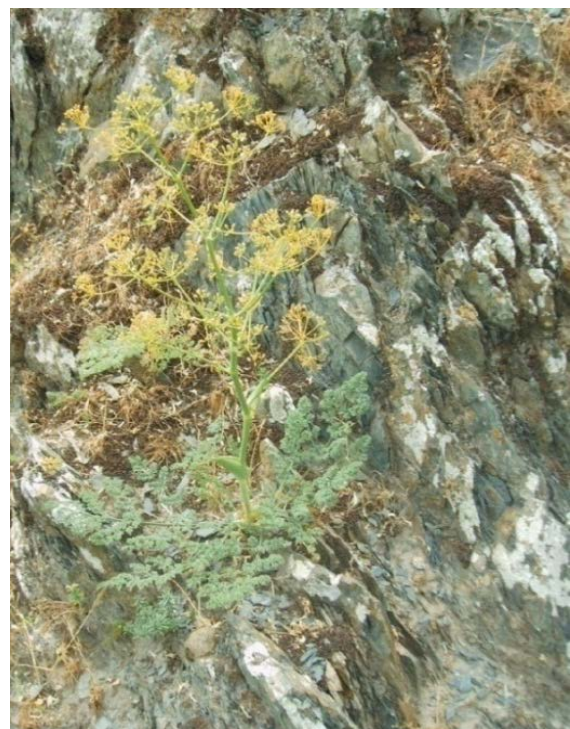

(d)

Figure 1. The flowering process of polycarp species genus of Ferula.

from $1-1.5$ to $2-2.5$ days. Throughout its length, there is an abundant release of nectar. After 2 - 3 days after the end of the stamens phase marked differentiation stigmas and offensive pistillate phase, which lasts 2 - 3 days and is characterized by a secondary, more copious nectar. The main type of pollination in the studied species is the cross, which is entomophilous. Geitenogamy is possible only within the entire inflorescence and is a reserve type of pollination. Self-pollination within the flower is excluded in view of the pronounced propresence [6].

During the pollination of flowers for species of the species, a large role is played by the beekeeping ones-Haliotus quadrioinetus Fabr., Haliotus sezintus 


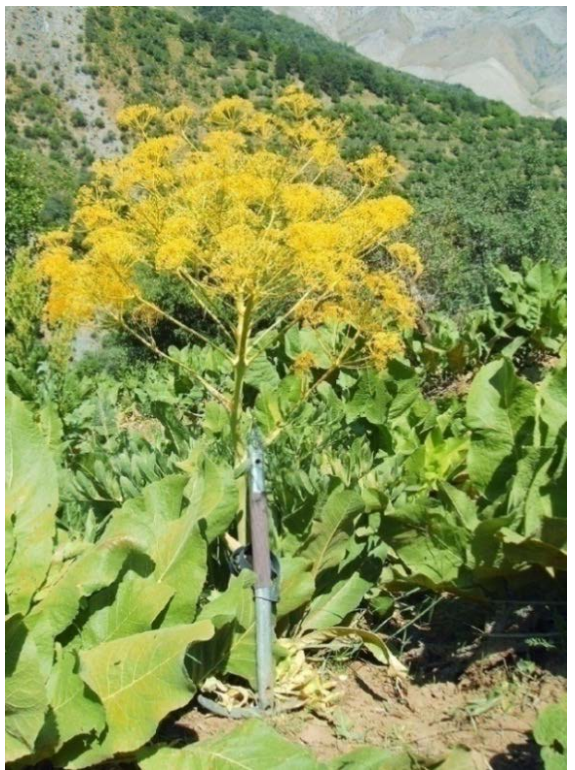

(a)

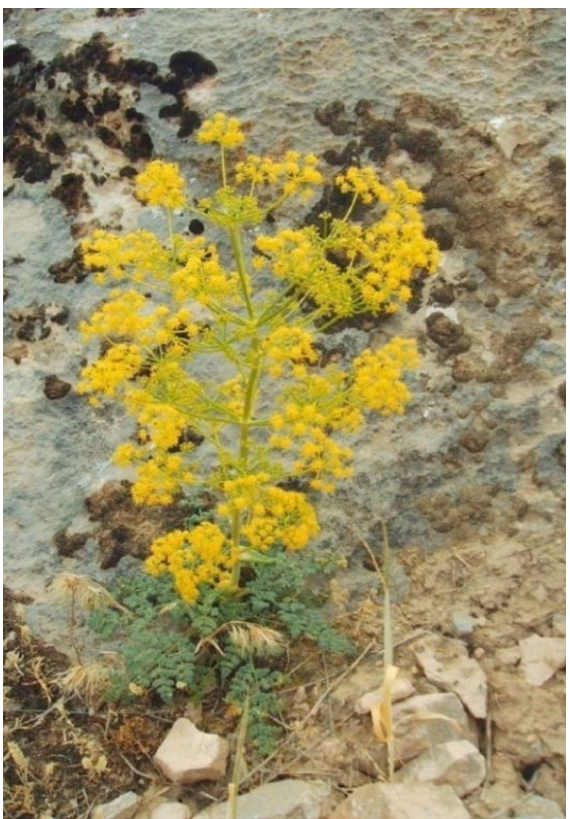

(c)

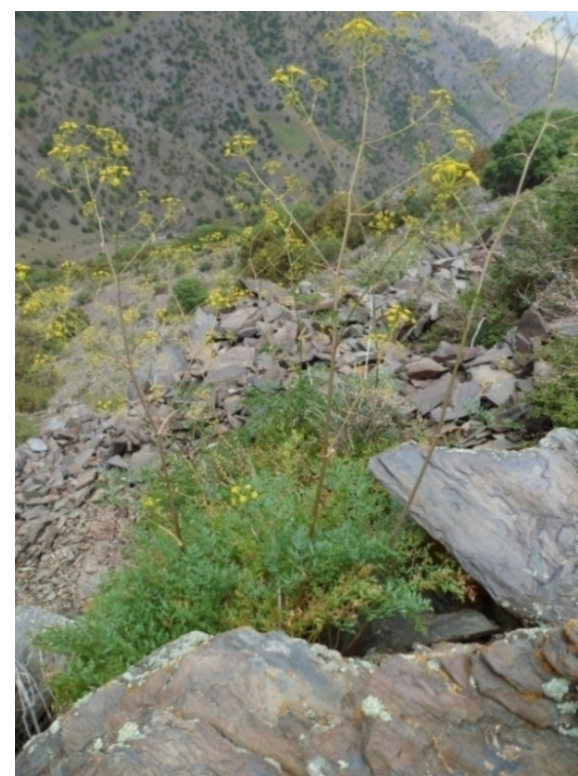

(b)

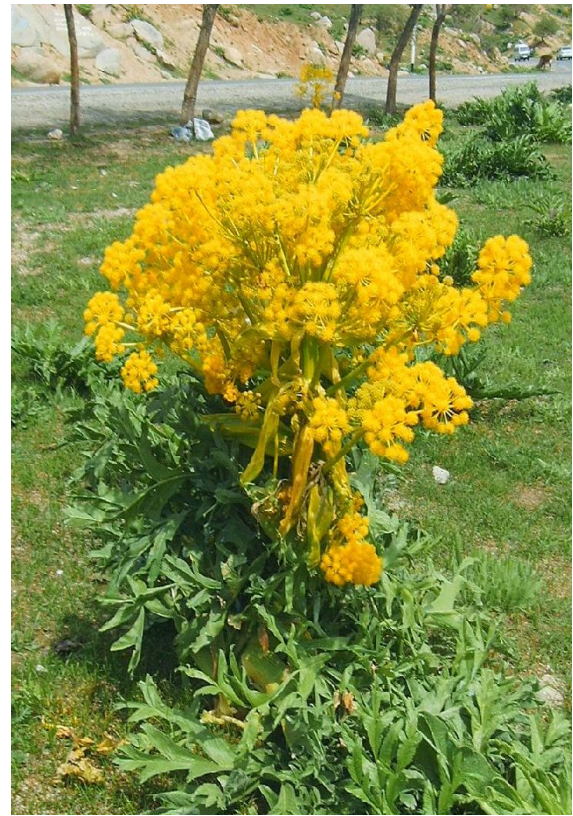

(d)

Figure 2. The flowering process of some Ferula species in the Western Pamir-Alai.

L., Andrea cinearia L., Mellituge clavornus, and Megchile argetata, Anhidium diodema, Litheagus monogerus and others collect pollen [9].

\section{Conclusion}

Thus, we studied the biology of flowering of 4 species of Ferula. It is established that they belong to the daytime flowering types. Polycarp species bloom in the 4 - 5 years of vegetation and fruiting for $10-15$ years. They form $1-3$ generative 
shoots. Monocarp species-F. helenae forms one generative shoot and blooms from 7 - 8 years of vegetation, then dies off. Within one generative shoot at polycarp flowering lasts an average of 4, 2 days (from 3.5 to 6.5). Blooming of bisexual flowers in polycarps lasts an average of 28 hours. Bisexual flowers located in the central umbrellas of the paracodia, open from 6 to 22 hours. In nature, the peak opening of flowers in F. ovina, F. angrenii, F. dshizakensis is $12-14$ hours, and in F. helenae-10 - 12 hours.

\section{Conflicts of Interest}

The authors declare no conflicts of interest regarding the publication of this paper.

\section{References}

[1] Ahmedkhodjaeva, Kh.S. and Kurmukov A.G. (1974) About Estrogenic Properties of Substances Isolated from Ferula. Animal Hormones and Hormonal Preparations. 32-33.

[2] Rakhmankulov, U., Melibaev, S. and Saidkhodjaev, A.I. (1981) Middle Asia Species of the Genus Ferula L. Source of Sesquiterpene Derivatives. Biological Features and Distribution of Promising Medicinal Plants. Fan, Tashkent, 138-153.

[3] Rasulov, M., Rakhmankulov, U. and Rasulov, O. (1995) Flowering and Polishing of Some Species of Ferula L. Actual Problems of Botany. Conf., Tashkent, 89.

[4] Pimenov, M.G. (1974) A New Species of Ferula from the Subgenus Narthex (Falcon) Drude. Bull. Ch. Bot. Garden of the Academy of Sciences of the USSR, 94, 54-58.

[5] Rakhmankulov, U. (1995) The Flowering Biology of Some Ferula in the Nuratau Mountains. Symposium Materials, Tashkent, 12-14 December 1995.

[6] Lee, A.D. (1959) On the Integrated Use of the Capric-Ferula assa-foetida L. Uzb. Biol. Journal., No. 3, 80-81.

[7] Rakhmankulov, U. and Melibaev, S.A. (1982) New Species of the Genus Ferula L. (Apiaceae) from the Nuratau Mountains. News of the Systematics of Higher Plants, 19, 117-119.

[8] Bogdasarova, M.H. (1990) Biology of Flowering and Cytoembryology of Some Species of Ferula L. of Uzbekistan. Author's Abstract. PhD. Thesis, Biological Sciences, Tashkent, 22.

[9] Ponomarev, A.N. (1960) The Study of Flowering and Pollination of Plants. Field Geobotany, 2, 9-19.

[10] Ponomarev, A.N. (1960a) On Prodrandry in Umbelliferae. Doklady Akademii Nauk SSSR, 3, 750-752. 